\title{
Effect of Cooling Rate and Titanium Additions on Microstructure of Thin-Walled Compacted Graphite Iron Castings
}

\author{
Marcin GÓRNY, ${ }^{1) *}$ Magdalena KAWALEC, ${ }^{1)}$ Gabriela SIKORA ${ }^{1)}$ and Hugo LOPEZ ${ }^{21}$ \\ 1) AGH-University of Science and Technology, Reymonta Str. 23, 30-059 Krakow, Poland. \\ 2) UWM University of Wisconsin-Milwaukee, P.O. Box 784, Milwaukee, WI 53201, USA.
}

(Received on February 19, 2014; accepted on May 26, 2014)

\begin{abstract}
This article addresses the effect of cooling rate and of titanium additions on the exhibited microstructure of thin-walled compacted graphite iron (TWCI) castings as determined by changing molding media, section size and Ferro Titanium. The research work was carried out on $\mathrm{TWCl}$ castings and reference castings of $2-5 \mathrm{~mm}$ and $13 \mathrm{~mm}$ wall thickness, respectively. Various molding materials were employed (silica sand and insulating sand "LDASC") to achieve different cooling rates. Thermal analysis was implemented for determinations of the actual cooling rates at the onset of solidification. This study shows that the cooling rates exhibited in the TWCl castings varies widely $\left(70-14^{\circ} \mathrm{C} / \mathrm{s}\right)$ when the wall thickness is changed from 2 to $5 \mathrm{~mm}$. In turn, this is accompanied by a significant variation in the compacted graphite fraction. The resultant cooling rates were effectively reduced by applying an insulating sand in order to obtain the desired graphite compactness. In addition, good agreement was found between the theoretical predictions of the solidification process and the experimental outcome. Ti additions in combination with LDASC sand molds were highly effective in promoting the development of over $80 \%$ compacted graphite in castings with wall thicknesses of 2 and $3 \mathrm{~mm}$ as evidenced by quantitative metallographic analyses.
\end{abstract}

KEY WORDS: compacted graphite iron; cooling rate; thermal analysis; microstructure.

\section{Introduction}

Current trends in the casting market are driving the need for strong cast irons with reduced weight when compared with gray iron parts. These cast irons must possess improved machinability, thermal-fatigue resistance, high damping capacity, improved casting mold yield and castability. In this sense, thin-walled compacted graphite iron (TWCI) castings provide a cost-effective solution to meet these challenges. Compacted Graphite Iron (CGI) also known as Vermicular Graphite Iron is a modern engineering alloy with attractive features that enable its use in the automotive industry. ${ }^{1-6)}$ In CGI, graphite exhibits an intermediate shape from the view point of compactness between flake graphite and spheroidal graphite.

The exhibited CGI microstructures are strongly influenced by a large number of factors (chemical composition, cooling rate, liquid treatment, and heat treatment). During the solidification process ${ }^{2,7-9)}$ the cooling rates exhibited by a given casting are primarily a function of the section size, pouring temperature, and the material mold ability to absorb heat. Increasing cooling rates have a strong effect on the graphite morphology and hence on the resultant mechanical properties. In particular, high cooling rates lead to an increase in the chilling tendency which is manifested as a high hardness and brittleness including poor machinability.

* Corresponding author: E-mail: mgorny@agh.edu.pl

DOI: http://dx.doi.org/10.2355/isijinternational.54.2288
The challenge of producing sound TWCI castings is not a simple one since it is closely related to the strong effect of a wide range of cooling rates upon solidification. ${ }^{10,11)}$ Moreover, there is limited data on cooling rate-microstructure relationships in TWCI castings, which is crucial for predictions of CGI castings. ${ }^{12-14)}$ Hence, this work is aimed at investigating the effect of wall thickness on the exhibited cooling rates and on the resultant CGI microstructures. In addition, the effect of $\mathrm{Ti}$ additions and the use of low thermal conductivity sand molds is considered in this work.

\section{Experimental}

The experimental melts were produced in an electric induction furnace of intermediate frequency and a $15 \mathrm{~kg}$ capacity crucible. The furnace charge consisted of Sorelmetal, technically pure silica, $\mathrm{Fe}-\mathrm{Mn}$, and steel scrap. Melting was carried out at $1763 \mathrm{~K}\left(1490^{\circ} \mathrm{C}\right)$, with the bath held at temperature for $2 \mathrm{~min}$. This was followed by vermicularization and inoculation operations using a bell method. For the vermicularization process, $\mathrm{Fe}-\mathrm{Si}-\mathrm{Mg}(6 \% \mathrm{Mg})$, as well as $\mathrm{Fe}-\mathrm{Ti}$ were used, while a $\mathrm{Fe}-\mathrm{Si}$ alloy $(75 \% \mathrm{Si}, 0.75-1.25 \%$ $\mathrm{Ca}, 0.75-1.25 \% \mathrm{Ba}, 0.75-1.25 \% \mathrm{Al}$ ) was used for inoculation. The inoculant added in an amount of $0.6 \mathrm{wt} . \%$. The chemical composition of the investigated iron is given in Table 1. The pouring temperature was approximately $1673 \mathrm{~K}$ $\left(1400^{\circ} \mathrm{C}\right)$. Experimental castings applied in investigations were test blocks, according to the ASTM A 536-84 standard, with plate section sizes of $\mathrm{g}=2,3,5$ and $13 \mathrm{~mm}$, 
Table 1. Chemical composition of CGI castings.

\begin{tabular}{ccccccccccccc}
\hline \multicolumn{10}{c}{ Chemical composition (Wt.\%) } \\
$\begin{array}{c}\text { Heat } \\
\text { No. }\end{array}$ & $\mathrm{C}$ & $\mathrm{Si}$ & $\mathrm{Mn}$ & $\mathrm{P}$ & $\mathrm{S}$ & $\mathrm{Cr}$ & $\mathrm{Ni}$ & $\mathrm{Cu}$ & $\mathrm{V}$ & $\mathrm{Al}$ & $\mathrm{Ti}$ & $\mathrm{Mg}$ \\
\hline I & 3.63 & 2.47 & 0.03 & 0.026 & 0.017 & 0.03 & 0.00 & 0.05 & 0.007 & 0.010 & 0.009 & 0.010 \\
II & 3.66 & 2.55 & 0.04 & 0.027 & 0.020 & 0.03 & 0.01 & 0.04 & 0.011 & 0.010 & 0.070 & 0.005 \\
III & 3.65 & 2.53 & 0.05 & 0.030 & 0.010 & 0.03 & 0.03 & 0.01 & 0.010 & 0.010 & 0.095 & 0.020 \\
IV & 3.60 & 2.55 & 0.05 & 0.023 & 0.018 & 0.04 & 0.04 & 0.06 & 0.010 & 0.021 & 0.133 & 0.021 \\
V & 3.63 & 2.56 & 0.04 & 0.030 & 0.018 & 0.03 & 0.04 & 0.05 & 0.010 & 0.020 & 0.135 & 0.022 \\
\hline
\end{tabular}
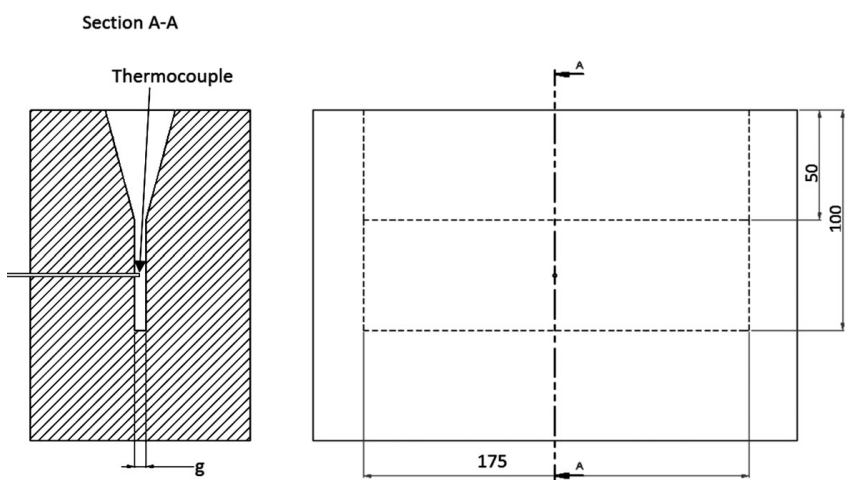

Fig. 1. Schematic of the test block casting.

respectively in the working part (Fig. 1). The sand molds were made using conventional green molding sand consisting of silica sand, bentonite ( $7 \mathrm{wt} . \%)$, water/bentonite ratio of 0.4 and a granularity of $100-200 \mu \mathrm{m}$.

In addition, sand molds were made using Low-Density Alumina-Silicate Ceramic (LDASC, composition 25-45\% $\mathrm{Al}_{2} \mathrm{O}_{3}$ and $55-75 \% \mathrm{SiO}_{2}$ ) whose heat transfer properties are drastically reduced (approx. by 4 fold) when compared with those of silica sands. ${ }^{13,14)}$ Moreover, the sand is characterized by a low density $0.35-0.45 \mathrm{~g} \cdot \mathrm{cm}^{-3}$. SEM microphotographs of LDASC sand are shown in Fig. 2.

The molds were instrumented with Pt/PtRh10 thermocouples of $0.1 \mathrm{~mm}$ diameter and with their tips located in the geometrical center of each mold cavity (Fig. 1). An Agilent 34970A electronic module was employed for temperature recording.

Metallographic characterization was made using a Leica MEF 4M microscope and a QWin v3.5 quantitative analyzer at various magnifications in order to determine the graphite and matrix morphologies. The analysis was based on line scans of the measuring area for measurements of the arithmetical average of graphite nodule fractions in the microstructure. At least five areas in the central part of the sample were used for these measurements.

Brinell hardness, HBW measurements were made in an HPO-250 hardness tester and tensile testing (ultimate tensile strength, UTS, $0.2 \%$ proof strength, $\mathrm{PS}_{0.2}$ and elongation, A) was performed on flat samples in a universal Zwick/Roell Z050, following the ASTM E8M 6.2 standard. In addition, samples were examined by a JEOL JSM-5500LV Scanning Electron Microscope (SEM) operated at $20 \mathrm{kV}$. (a)

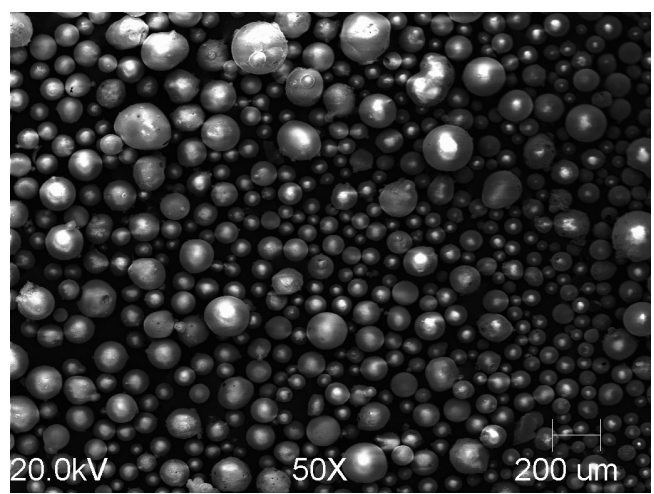

(b)

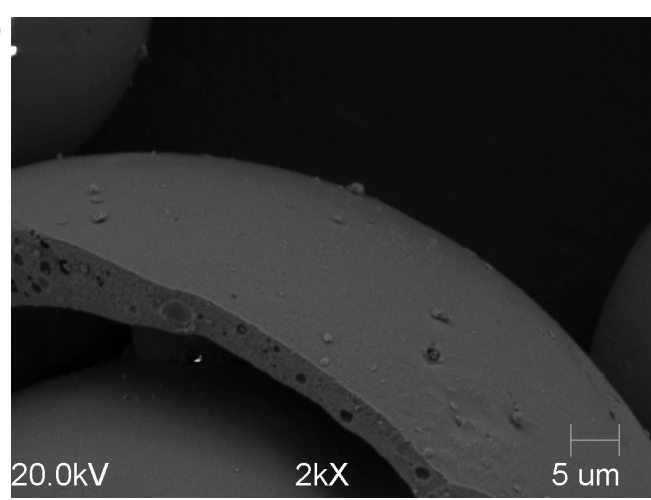

Fig. 2. SEM microphotographs of LDASC sphere sand.

\section{Results and Discussion}

\subsection{Thermal Analysis}

Figure 3 shows the resultant cooling curves in the investigated iron castings. In this figure, the equilibrium graphite eutectic solidification temperature $\left(T_{s}\right)$ and the cementite eutectic temperature $\left(\mathrm{T}_{\mathrm{c}}\right)$ are highlighted. These temperatures were determined using the following expressions: ${ }^{15)}$

$$
\begin{array}{r}
\mathrm{T}_{\mathrm{s}}\left({ }^{\circ} \mathrm{C}\right)=1153.90+5.25 \mathrm{Si}-14.88 \mathrm{P} \\
\mathrm{T}_{\mathrm{c}}\left({ }^{\circ} \mathrm{C}\right)=1130.56+4.06(\mathrm{C}-3.33 \mathrm{Si}-12.58 \mathrm{P})
\end{array}
$$

In Eq. (2), $T_{c}$ is the transition temperature for the solidification of cementite eutectic from graphite eutectic, or the chill formation temperature. ${ }^{16)}$ Also, from Fig. 3, it can be observed that as the wall thickness decreases (cooling rate increases), the minimal temperature at the onset of graphite eutectic solidification $\left(\mathrm{T}_{\mathrm{m}}\right)$ decreases. Thus, within the temperature range $\Delta \mathrm{T}_{\mathrm{sc}}=\mathrm{T}_{\mathrm{s}}-\mathrm{T}_{\mathrm{c}}$, graphite eutectic is the only growing structure (without any chills).

From the thermal analysis curves, cooling rates (Q) near the equilibrium graphite eutectic solidification temperature $\left(T_{\mathrm{s}}\right)$ were established. Figure 4 shows a cooling curve and its corresponding cooling rate curve for compacted graphite iron.

It is well known that the section sensitivity of compacted graphite iron is lower than for gray iron, which in turn contributes to the homogeneity of the casting structure. Yet, in thin-walled castings, the section sensitivity of compacted graphite iron should be taken into account due to the high cooling rate ranges involved. ${ }^{10)}$ In this case, there is a vast tendency for defect formation, particularly structural inhomogeneities including the development of chilled iron. As a first approximation, in sand castings it can be assumed that 


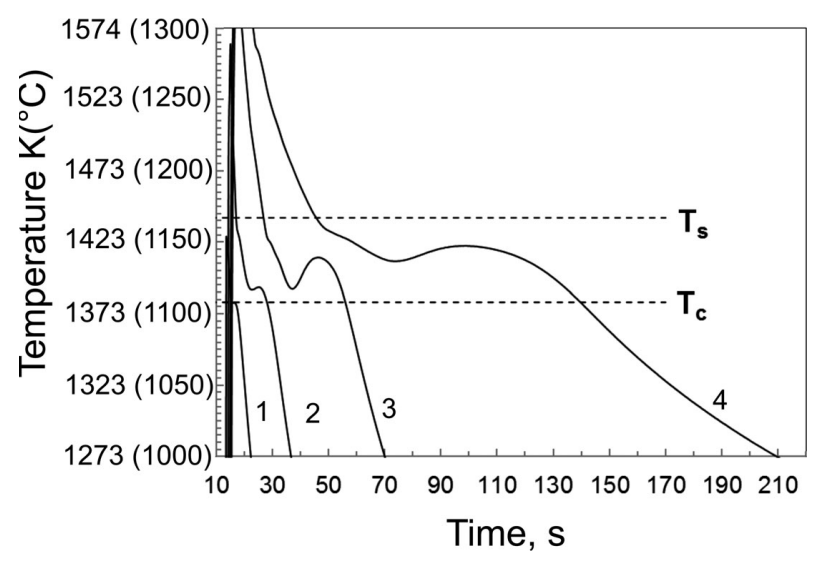

Fig. 3. Cooling curves for compacted graphite iron in samples with different wall thicknesses and foundry molds: Curves 1 and 2: Foundry mold with silica sand (Heat No. IV) for wall thicknesses of 2 and $3 \mathrm{~mm}$, respectively, curves 3 and 4 : Foundry mold with LDASC sand (Heat No. V) and wall thicknesses 2 and $3 \mathrm{~mm}$, respectively.

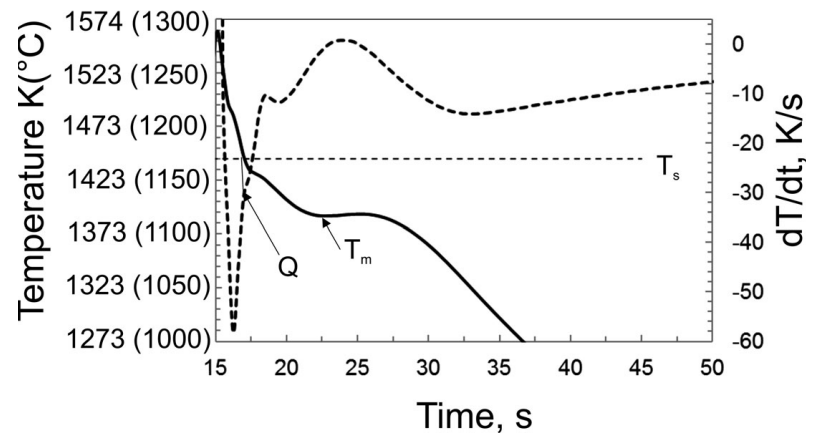

Fig. 4. Cooling curve (solid line) and cooling rate curve (dotted line) for compacted graphite iron in a 3-mm wall thickness (Heat No. IV). Q - cooling rate of compacted graphite iron at the onset of graphite eutectic solidification, $\mathrm{T}_{\mathrm{m}}$ - minimal temperature at the onset of graphite eutectic solidification.

heat transfer is mainly determined by the properties of the sand mold. From a heat balance for the heat flux in the casting, (i.e. the heat flux extracted from the casting into the mold and the heat flux generated during solidification) the cooling rate can be expressed as. ${ }^{16)}$

$$
\mathrm{Q}=\frac{8 \mathrm{~T}_{\mathrm{s}} \mathrm{a}^{2}}{\pi \mathrm{c}^{2} \mathrm{~s}^{2} \ln \frac{\mathrm{T}_{\mathrm{i}}}{\mathrm{T}_{\mathrm{s}}}}
$$

where: a - material mold ability to absorb heat, c - specific heat of the cast iron, $s$ - wall thickness of the casting and $T_{i}$ - initial temperature of the metal in the mold cavity just after pouring.

Figure 5 shows the cooling rates estimated using Eq. (3) as well as the experimental data obtained from the thermal analysis curves.

Notice from this figure that there is good agreement between the theoretical predictions and the experimental outcome. From the theoretical analysis (Eq. (3)), it is shown that the cooling rate (except for the wall thickness of the casting) is mainly affected by the mold heat transfer properties (a) and by $\mathrm{T}_{\mathrm{i}}$. In particular, molding materials with a low ability to absorb heat (e.g., LDASC sand) have a significant effect in reducing the cooling rates. Notice that

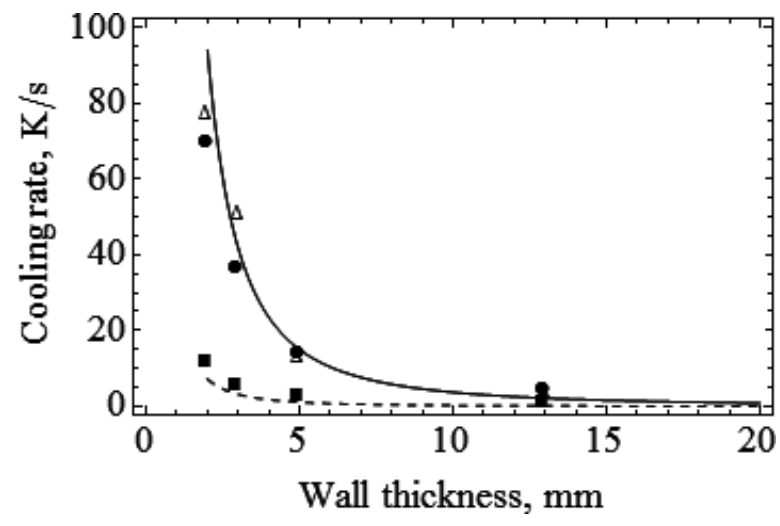

Fig. 5. Effect of wall thickness on the cooling rate of the experimental castings: Solid curve - calculations made for $\mathrm{c}=$ $5.95 \mathrm{~J} \mathrm{~cm}^{-3 \circ} \mathrm{C}^{-1} ; \mathrm{T}_{\mathrm{e}}=1167^{\circ} \mathrm{C} ; \mathrm{T}_{\mathrm{i}}=1400^{\circ} \mathrm{C} ; \mathrm{a}=0.1 \mathrm{~J} /$ $\left(\mathrm{cm}^{2 \circ} \mathrm{C} \mathrm{s}^{1 / 2}\right)$, dotted curve - calculations made for $\mathrm{c}=5.95 \mathrm{~J}$ $\mathrm{cm}^{\circ} \mathrm{C}^{-1} ; \mathrm{T}_{\mathrm{e}}=1167^{\circ} \mathrm{C} ; \mathrm{T}_{\mathrm{i}}=1400^{\circ} \mathrm{C} ; \mathrm{a}=0.025 \mathrm{~J} /\left(\mathrm{cm}^{2 \circ} \mathrm{C} \mathrm{s}^{1 / 2}\right)$; $\Delta$ - experimental points for green sand molds (Heat No. I), - experimental points for green sand molds (Heat No. IV), - experimental points for LDASC sand molds (Heat No. V).

when LDASC sand is used as casting molds $\left(\mathrm{a} \approx 0.025 \mathrm{~J}^{\circ} \mathrm{C}^{-1}\right.$ $\left.\mathrm{cm}^{-2} \mathrm{~s}^{-1 / 2}\right)$ instead of silica sand $\left(\mathrm{a} \approx 0.10 \mathrm{~J}^{\circ} \mathrm{C}^{-1} \mathrm{~cm}^{-2} \mathrm{~s}^{-1 / 2}\right)$, the cooling rates experienced by a TWCI with a $2 \mathrm{~mm}$ wall thickness decrease by over 5 fold (see Fig. 5).

In addition, it is found that the cooling rates exhibited in TWCI with a wall thickness of $3 \mathrm{~mm}$ are similar to those obtained in conventional castings of $13 \mathrm{~mm}$ wall thickness when produced using silica sand (Fig. 5). Hence, the use of LDASC sand materials in the foundry process can dramatically improve metal flow, reduce misruns in thin sections, and slow down solidification rates in TWCI. In a related work, Showman and Aufderheide ${ }^{13,14)}$ reported that casting design is plausible by the use of insulating molding materials, other than conventional sand mold castings. Hence, the development of insulating sand materials which provide a significant reduction in the heat absorption thermal properties can be highly valuable for the production of sound TWCI castings.

\subsection{Microstructural Features and Mechanical Proper- ties}

Figure 6 shows the exhibited microstructures found in thin wall castings from heats I-V. These results are also given in Table 2. Metallographic examinations revealed a significant effect of $\mathrm{Ti}$ additions on the compacted graphite, particularly in thin walled castings. However, the addition of Ti requires the addition of extra magnesium to avoid any risks for graphite flake formation (see Fig. 6(b)). Thus, it is common to set a limit of $20 \%$ nodularity in order to meet CGI specifications. ${ }^{8,9,17)}$ In the case of thin-walled castings, the natural tendency of CGI is to solidify with a higher nodularity in thin outer walls $(<4-5 \mathrm{~mm})$ with up to $50 \%$ nodularity. ${ }^{3)}$ Studies show that in TWCI castings with a wall thickness of $5 \mathrm{~mm}$, additions of $0.13 \%$ Ti result in increases in the compacted graphite fraction above $80 \%$, thus satisfying the ASTM standard. ${ }^{17)}$ This study shows that the use of $0.13 \% \mathrm{Ti}$ in thin-walled castings has a much stronger effect on the solidification of compacted graphite in comparison with castings with thicker sections (Table 2). Analysis of the 
(a)

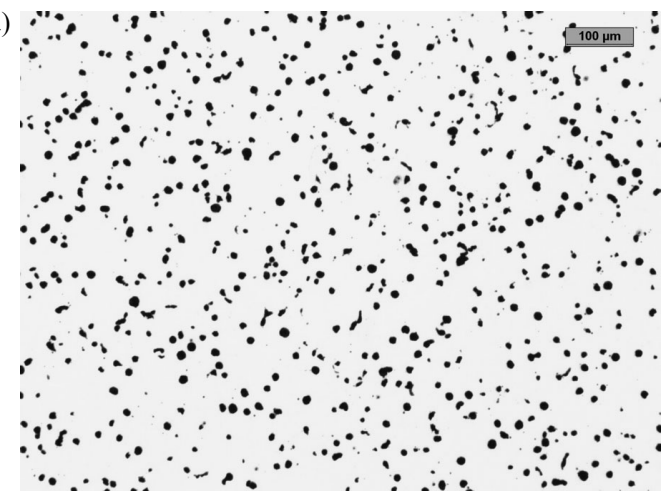

(c)

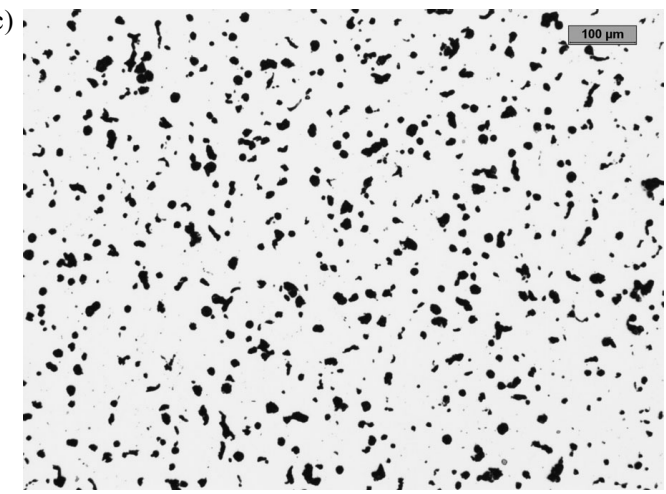

(e)

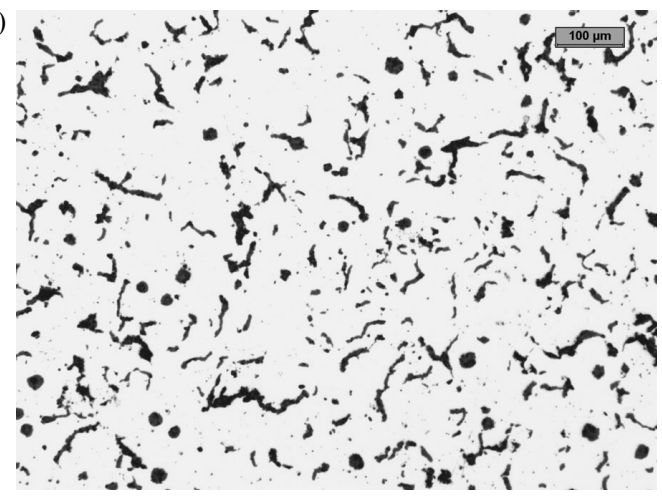

(b)

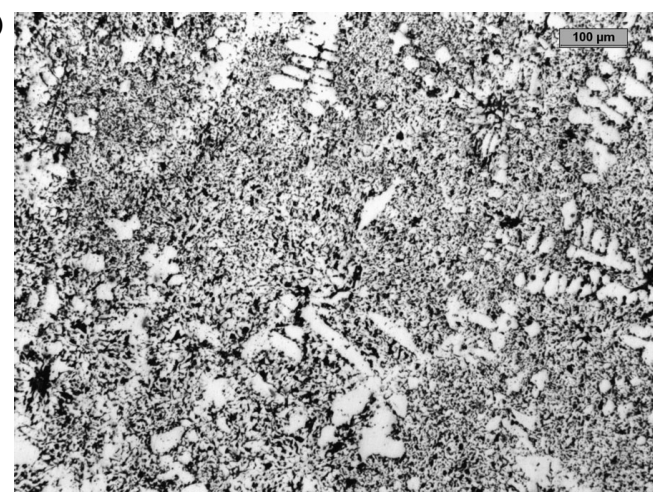

(d)

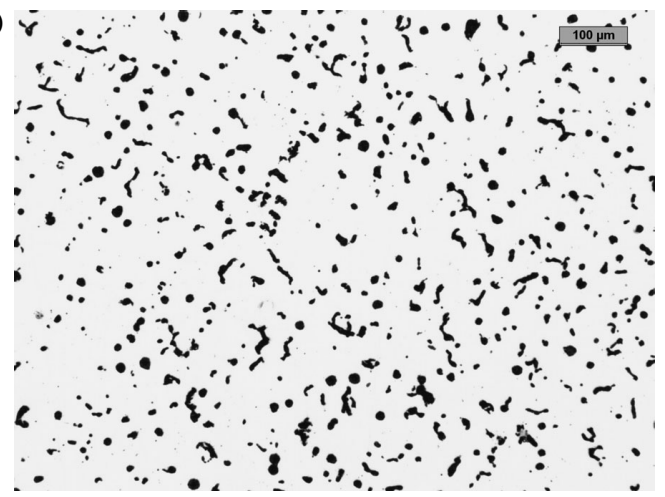

Fig. 6. Exhibited TWCI microstructures of test block castings with a wall thickness of $3 \mathrm{~mm}$ : (a) Heat I, (b) heat II, (c) heat III, (d) heat IV and (e) heat V. Mag. 100x. No etchant used.

cast iron matrix shows that the addition of Ti slightly decreases the ferrite fraction in the casting (Table 2).

In this work, for TWCI castings with a wall thickness of $3 \mathrm{~mm}$, the nodular graphite fraction was reduced from $73 \%$ for Heat No. I down to $34 \%$ through the addition of $0.13 \%$ Ti (Heat No. IV).

Notice that in castings with wall thicknesses of 2 and $3 \mathrm{~mm}$, Ti additions as an anti-nodularizing element do not allow to meet the ASTM specification of a required compacted graphite fraction above $80 \%$. In contrast, metallographic evaluations clearly show that the use of LDASC sand significantly reduces the cooling rates (Fig. 5). In turn, this causes a significant increase in the compacted graphite fraction exhibited in the TWCI castings. When LDASC sands are employed in castings with wall thicknesses of 2 and $3 \mathrm{~mm}$ the compacted graphite fraction exceeds $90 \%$. Thus, it satisfies the ASTM standard concerning a minimum volume fraction of at least $80 \%$. In particular, notice that the compacted graphite fraction, as well as the graphite size in TWCI with a wall thickness of $3 \mathrm{~mm}$ using LDASC sands is similar to that found in castings with thick wall thickness- es of approx. $13 \mathrm{~mm}$ obtained using silica sand molds (see Fig. 7).

Similar values of cooling rates, at the beginning of the solidification, of castings with a wall thickness of $3 \mathrm{~mm}$, using an insulating LDASC sand to those castings of $13 \mathrm{~mm}$ wall thickness, obtained in conventional silica sand, resulted in obtaining similar microstructures (Fig. 7). The study of the mechanical properties have shown that values of tensile strength (UTS), $0.2 \%$ proof strength $\left(\mathrm{PS}_{0.2}\right)$, hardness (HBW), and elongation (A) of the samples taken from the castings with a wall thickness of $3 \mathrm{~mm}$, made in molds using LDASC sand (Heat No. V: UTS $=398 \mathrm{MPa}, \mathrm{PS}_{0.2}=292 \mathrm{MPa}$, $\mathrm{HBW}=171, \mathrm{~A}=6.8 \%$ ) are similar to those taken from the castings with a wall thickness of $13 \mathrm{~mm}$ made in silica sand (Heat No. I: UTS $=378 \mathrm{MPa}, \mathrm{PS}_{0.2}=280 \mathrm{MPa}, \mathrm{HBW}=155$, $A=8.8$ ). In the case of the results of mechanical properties of castings obtained in silica sand molds one can see that no significant increase in the hardness occurs for Ti addition up to $0.13 \%$. It can be seen that the tensile strength slightly increases with the addition of $\mathrm{Ti}$ up to $0.09 \% \mathrm{Ti}$. Further increasing the titanium causes a decrease in both the tensile 
Table 2. Effect of Ti on the nodular graphite fraction, ferrite fraction and mechanical properties in TWCI castings.

\begin{tabular}{ccccccccc}
\hline $\begin{array}{c}\text { Heat } \\
\text { No. }\end{array}$ & $\begin{array}{c}\text { Ti } \\
\text { additions } \\
{[\%]}\end{array}$ & $\begin{array}{c}\text { Wall } \\
\text { thickness } \\
{[\mathrm{mm}]}\end{array}$ & $\begin{array}{c}\text { Graphite } \\
\text { nodule } \\
\text { fraction } \%\end{array}$ & $\begin{array}{c}\text { Ferrite } \\
\text { fraction } \\
\%\end{array}$ & $\begin{array}{c}\text { UTS, } \\
\mathrm{MPa}\end{array}$ & $\begin{array}{c}\mathrm{PS}_{0.2}, \\
\mathrm{MPa}\end{array}$ & $\mathrm{A}, \%$ & $\mathrm{HBW}$ \\
\hline I & 0.00 & 2 & 92 & 28 & 723 & 540 & 5.1 & 237 \\
III & 0.09 & 2 & 64 & 23 & 702 & 523 & 3.2 & 225 \\
IV & 0.13 & 2 & 50 & 26 & 688 & 519 & 2.0 & 216 \\
V & 0.13 & 2 & 10 & 84 & 389 & 287 & 8.4 & 176 \\
I & 0.00 & 3 & 73 & 40 & 595 & 407 & 6.0 & 223 \\
III & 0.09 & 3 & 46 & 40 & 622 & 421 & 5.4 & 232 \\
IV & 0.13 & 3 & 34 & 30 & 516 & 377 & 3.7 & 238 \\
V & 0.13 & 3 & 7 & 87 & 398 & 292 & 6.8 & 171 \\
I & 0.00 & 5 & 47 & 65 & 526 & 388 & 9.2 & 173 \\
III & 0.09 & 5 & 29 & 74 & 466 & 331 & 6.1 & 181 \\
IV & 0.13 & 5 & 17 & 56 & 443 & 319 & 6.1 & 183 \\
I & 0.00 & 13 & 20 & 90 & 378 & 280 & 8.8 & 155 \\
III & 0.09 & 13 & 17 & 85 & 387 & 283 & 6.4 & 160 \\
IV & 0.13 & 13 & 15 & 90 & 363 & 276 & 6.4 & 154 \\
\hline & & & & & & & &
\end{tabular}

(a)

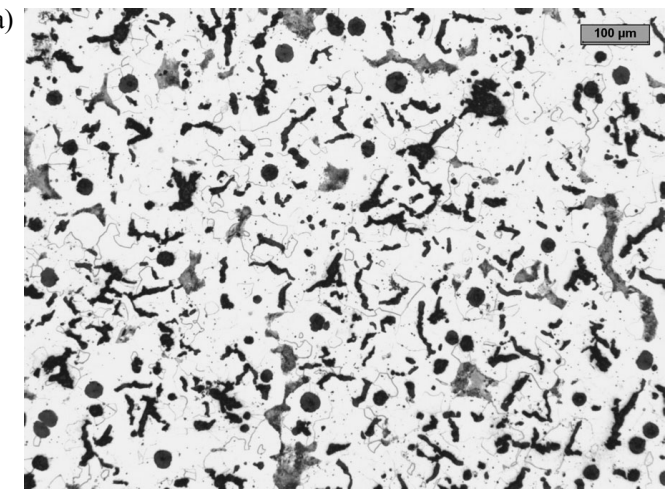

(b)

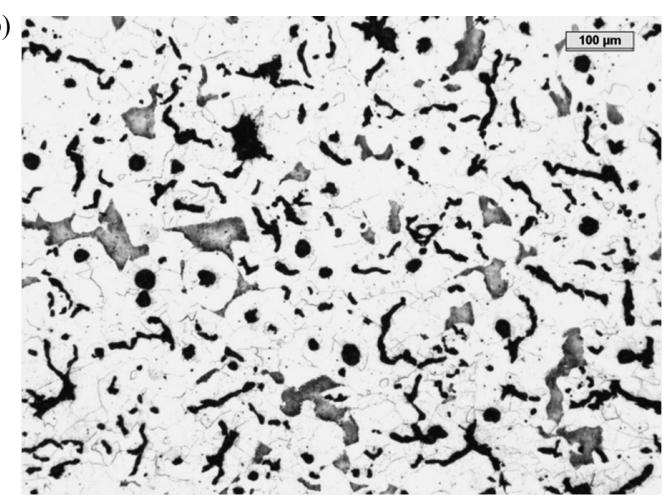

Fig. 7. Microstructures of test block castings with wall thicknesses of (a) $3 \mathrm{~mm}$ (Heat No. V: using LDASC sand) and (b) $13 \mathrm{~mm}$ (Heat No. I: using silica sand). Nital etched samples.

strength and the elongation of thin-walled iron castings. This is due to an increase in the compacted graphite fraction in the cast iron microstructure, with a higher length to thickness ratio. In the case of reference casting $(\mathrm{g}=13 \mathrm{~mm})$, the addition of Ti does not appreciably affect the UTS, YS or HBW, while elongation is lowered to the level of $6.4 \%$.

The addition of $\mathrm{Ti}$ results in solidification of titanium carbides and titanium carbonitride in the form of faceted (a)

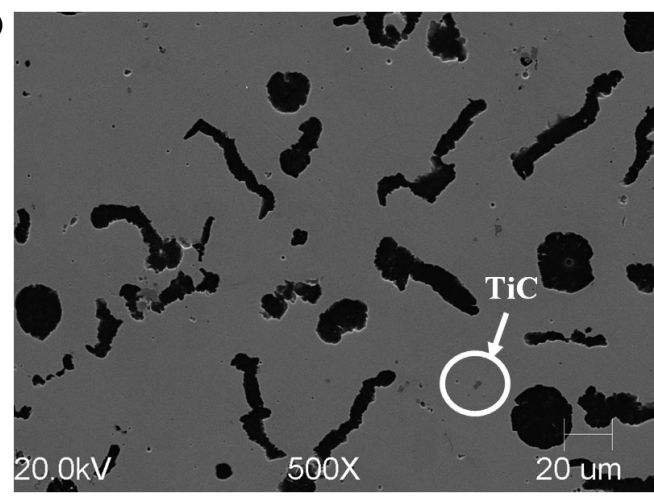

(b)

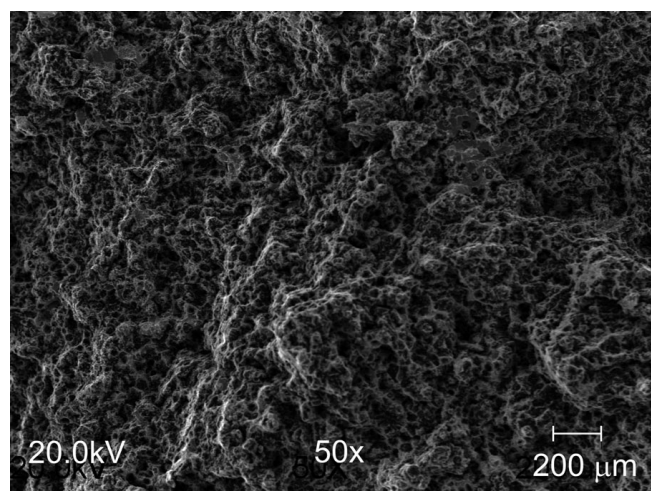

(c)

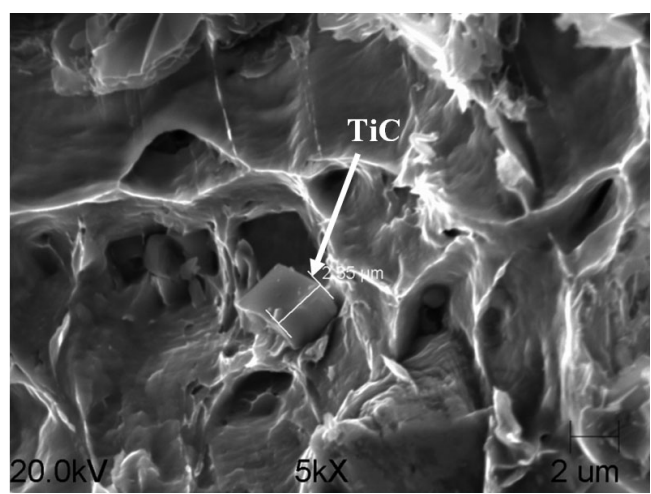

(d)

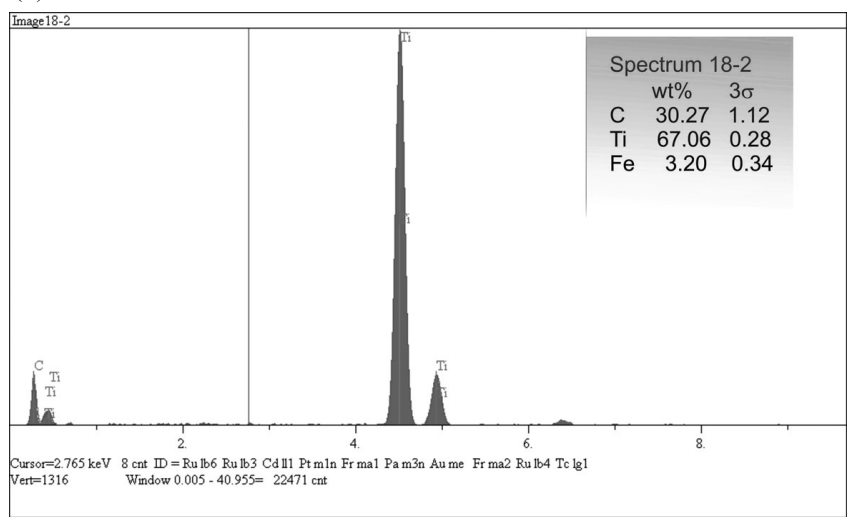

Fig. 8. (a) SEM microstructure of test block casting with a wall thickness of $3 \mathrm{~mm}$ from heat no. V, (b, c) SEM fractographs of tensile tested specimens, (d) EDS spectrum of TiC particle.

crystals. ${ }^{6,89)}$ The EDS analysis shows mainly the titanium carbides, which are created in the form of faceted crystals, evenly distributed in iron matrix. From metallographic observations result that their maximum size does not exceed $5 \mu \mathrm{m}$ and their volume fraction is much lower than $1 \%$. Titanium carbonitrides are present in the microstructure in trace 
amounts. Figure 8 show SEM microstructure, fractographs from of tensile tested specimens and EDS spectrum of TiC particle.

Hence, from this work, it is evident that there is a wide range of possibilities for compacted graphite iron production unattainable through the use of ordinary foundry sands. Accordingly, novel applications are envisaged such as in the design of diesel engine blocks, exhaust manifolds, gearbox housings, brake discs for high-speed trains, flywheels, ${ }^{3,18,19)}$ and other. Also from the view point of economics and ecology, thin-walled castings made of CGI can compete in terms of mechanical properties with "light" aluminum alloy castings. ${ }^{19)}$ Accordingly, CGI provides increasing potential for applications which conventional materials cannot offer such as in the design of 'compound' iron-plus-aluminum blocks. In this case, CGI possesses superior strength and stiffness when compared with gray iron and aluminum, thus providing original bore size and shape stability for engine block design. From the foregoing results it is clear that CGI provides an opportunity to meet the performance requirements of the next generation of engineered components, particularly cylinder blocks and heads.

\section{Conclusions}

Theoretical calculations were made and then compared with the experimental outcome on the effect of casting cooling rates at the onset of solidification in TWCI. It was found that the predictions of the theoretical analysis are in a good agreement with the experimental results.

In TWCI castings with wall thicknesses of $2-3 \mathrm{~mm}$ using an insulating sand, LDASC, the cooling rates exhibited and the graphite fraction were found to be at the level typically achieved in castings with a wall thickness of the order of $13 \mathrm{~mm}$ when using silica sand molds. Also, a homogeneous structure free from chills was obtained despite the high cooling rates expected in thin-walled castings.

In the case of silica molding sand, the cooling rates were found to vary between 70 and $14^{\circ} \mathrm{C} / \mathrm{s}$ in TWCI castings when the wall thickness was changed from 2 to $5 \mathrm{~mm}$. This was accompanied by a significant change in the compacted graphite fraction. The fraction of compacted graphite was effectively increased by employing an insulating LDASC molding sand. In turn, a structure in the compacted iron having more than $80 \%$ compacted graphite fraction was obtained, thus meeting the ASTM Standard specifications.

\section{Acknowledgements}

In Memory of Professor Edward Fraś, 1940-2013.

This work was supported by Polish NCN project no. 2013/09/B/ST8/00210.

\section{REFERENCES}

1) M. Konig and M. Wessen: Int. J. Cast Metal. Res., 23 (2010), 97.

2) M. Konig: Int. J. Cast Metal. Res., 23 (2010), 185.

3) S. Dawson and T. Schroeder: AFS Trans., 112 (2004), 1.

4) W. Guesser, T. Schroeder and S. Dawson: AFS Trans., 109 (2001), 1.

5) C. Farias, J. Benavente, T. Schroeder and S. Dawson: AFS Trans., 105 (1997), 947.

6) S. Dawson, I. Hollinger, M. Robbins, J. Daeth, U. Reuter and H. Schultz: The Effect of Metallurgical Variables on the Machinability of Compacted Graphite Iron, Society of Automotive Engineers Inc., (2001), http://www.uscti.com/u pages/publications/pdfs/ItemEThe EffectOfMetallurgicalVariablesOnMachinabilityCGI2001AEIStark.pdf, (accessed 2014.05.14)

7) H. Ledbetter and S. Datta: Z. Metallkd., 83 (1992), 195.

8) L. Sofroni, I. Riposan and I. Chria: Proc. of 2nd Int. Symp. on the Metallurgy of Cast Iron, Institute Battele, Georgi Pub. Co., Geneva, Switzerland, (1974), 179.

9) C. Podrzucki and A. Wojtysiak: Unalloyed Ductile Iron. Part II, Cast Iron with Vermicular Graphite, AGH University Press, Krakow, (1988), 1.

10) M. Gorny: Structure Formation of Ultra-Thin Wall Ductile Iron Castings, Akapit, Krakow, (2010), 8.

11) E. Fras, M. Gorny and H. F. Lopez: Int. Foundry Res., 61 (2009), 2.

12) S. Charoenvilaisiri, D. M. Stefanescu, R. Ruxanda and T. S. Piwonka: AFS Trans., 110 (2002), 1113.

13) R. E. Showman, R. C. Aufderheide and N. Yeomans: Mod. Cast., 96 (2006), 29.

14) R. E. Showman and R. C. Aufderheide: AFS Trans., 112 (2004), 823

15) B. Lux and W. Kurz: The Solidification of Metals, The Iron and Steel Institute, London, England, 110 (1967), 193.

16) E. Fraś, M. Górny and H. F. Lopez: ISIJ Int., 47 (2007), 259.

17) ASTM A842-85, Standard Specification for Compacted Graphite Iron Casting, American Society for Testing Materials, West Conshohoken, PA, (2009), DOI: 10.1520/A0842-85R09

18) H. Qiu and Z. Chen: China Foundry, 4 (2007), 261.

19) S. Dawson: Foundry Trade J., June (2011), 170. 